\title{
LOW DIMENSIONALITY MATERIALS: ORIGIN OF THE REDUCED DIMENSONALITY IN TIN(II) FLUORIDE- CONTAINING COMPOUNDS AND ITS STUDY BY X-RAY DIFFRACTION AND MÖSSBAUER SPECTROSCOPY
}

\author{
GEORGES DÉNÈS ${ }^{1}$, M. CECILIA MADAMBA ${ }^{1}$, HOCINE MERAZIG $^{2}$ \& ABDUALHAFED MUNTASAR ${ }^{1}$ \\ ${ }^{1}$ Laboratory of Solid State Chemistry and Mössbauer Spectroscopy, Department of Chemistry and Biochemistry, \\ Concordia University, Montreal, QC, Canada. \\ ${ }^{2}$ Unité de Recherche de Chimie de l'Environnement et Moléculaire Structurale CHEMS, \\ Université Mentouri, Constantine, Algeria.
}

\begin{abstract}
Isotropic materials have the same properties in all directions of space, with the same magnitude. Strict isotropy requires a spherical symmetry, hence a cubic unit-cell. All other crystal systems give rise to property anisotropy, i.e. direction dependence of properties and of their magnitude, although the anisotropy may often be weak enough to be quite insignificant. However, some materials show very strong anisotropy, owing to their layered structure, which is the result of unequal bond strength versus direction in space. Property anisotropy is usually the consequence of bonding anisotropy that gives anisotropic crystal growth, i.e. the crystals grow faster in some directions and slower in others, resulting in a crystallite shape that is often sheet-like (two-dimensional) or needle-like (one-dimensional). Many tin(II)-containing materials are found to have very strong low dimensionality: (1) $\mathrm{SnF}_{2} / \mathrm{MCl}(\mathrm{M}=$ alkali metals and $\mathrm{NH}_{4}$ ) give needle shaped crystals even long hair-shaped. For example, in $\mathrm{M}_{3} \mathrm{Sn}_{5} \mathrm{Cl}_{3} \mathrm{~F}_{10}$, the intersection of planes of lone pairs creates cleavage planes in two directions, giving needle shaped crystals. Extreme cases of two-dimensionality were observed in $\mathrm{MSnF}_{4}$, particularly in $\alpha-\mathrm{PbSnF}_{4}$. Bonding anisotropy in tin(II)-containing materials is due to the tin stereoactive lone pair, when the lone pairs cluster in sheets, since no bonding to tin can take place in the lone pair direction. This gives rise to high preferred orientation of polycrystalline samples. The presentation will show how the anisotropy of the tin(II) quadrupole doublet, measured on polycrystalline samples subjected to an extremely enhanced preferred orientation, can be used to predict the direction of the lone pairs in the unit-cell and this, in turn, explain the direction of the cleavage planes. The presentation will focus on the use of X-ray diffraction and Mössbauer spectroscopy to characterize highly anisotropic phases and understand their structure-textural properties.
\end{abstract}

Keywords: anisotropy, divalent tin, lone pair stereoactivity, low dimensionality, Mössbauer spectroscopy, $X$-ray diffraction.

\section{INTRODUCTION}

The report of the size of many properties of solids is often given by a scalar, i.e. a number that has only a magnitude, not a direction. The absence of direction dependence is valid for gases and homogeneous liquids. However, for crystalline solids, the magnitude of many properties is a function of direction, and it should therefore be given by vectors. In this case the full direction dependence of properties is represented by a tensor [1]. Among the properties that are direction dependent are thermal expansion, hydrostatic compressibility, thermal conductivity, electrical conductivity, as well as optical properties and strain/stress relationship. In order to measure the anisotropy of a property, a single crystal must be used and measurements must be done in several directions well defined relative to the crystal axes. In a perfectly randomized polycrystalline sample, the magnitude of the property will be the same in all directions of the random samples, and its value will be an average of its magnitudes in all directions of a single crystal. However, if the sample is not perfectly randomized, then the 
magnitude will be direction dependent and it will be a function of the anisotropy and of the discrepancy from perfect randomization. Of course, this can be a serious problem for devices used for practical applications. In addition, often, the higher the difficulty to randomize samples, the higher the anisotropy. This is due to a strong anisotropy of bonding. Graphite is a perfect example. It is a layered structure whereby carbon atoms are at the corners of a hexagon and each corner is shared between three hexagons, to form infinite planes of such hexagons. Overall $2 / 3$ are $\mathrm{C}-\mathrm{C}$ single bonds and $1 / 3$ are $\mathrm{C}=\mathrm{C}$ double bonds and resonance makes all bonds equal with a bond order of 1.33 and a bond length of $141 \mathrm{pm}$. Since there is no bonding between adjacent layers, the interlayer distance is much larger, $335 \mathrm{pm}$. This makes graphite a very highly anisotropic material. For example, its electrical conductivity in the planes is about 5000 times greater than in the perpendicular direction. The lack of interlayer bonding is also responsible for its excellent lubricating properties and its ability to be a host for the formation of intercalate compounds. The two-dimensional bonding system of carbon in graphite is due to its $\mathrm{sp}^{2}$ hybridization that gave a trigonal planar coordination, and no bond in the perpendicular direction. In the present work, it is shown that corrugated sheets of chloride ions in $\mathrm{BaClF}$ results in a significant amount of preferred orientation. In addition, it was discovered that stereoactive lone pairs in main group elements in a suboxidation state can cluster in sheets, such as no bonding can occur through the sheets of lone pairs, resulting in highly layered structures. A perfect example of this was observed in tetragonal black $\mathrm{SnO}$ and in isostructural yellow $\mathrm{PbO}$, litharge [2]. The present report is mostly concerned with the study of tin(II) halides, mainly fluorides and chloride fluorides, some of which are the best fluoride ion conductors, therefore their low dimensionality is due to clustering of the tin(II) lone pairs in sheets.

\section{THEORETICAL BACKGROUND ABOUT MÖSSBAUER SPECTROSCOPY AND BONDING IN DIVALENT TIN}

Crystallography uses X-ray or neutron diffraction to study of the whole crystal lattice. On the other hand, Mössbauer spectroscopy is a local probe. It is a nuclear spectroscopy, and therefore, it probes only specific nuclides, such as ${ }^{119} \mathrm{Sn}$ in this work. Therefore, by use of ${ }^{119} \mathrm{Sn}$ Mössbauer spectroscopy, we can study tin in compounds, and the way it interacts with its neighbors and with the entire solid lattice. The nuclear spins on ${ }^{119} \mathrm{Sn}$ are $1 / 2$ in the ground state and 3/2 in the first excited state. The ground state has no quadrupole moment; therefore, it remains unsplit $(\mid \pm 1 / 2>)$ in the absence of a magnetic field, even if an electric field gradient (e.f.g.) is present, while the first excited state has a quadrupole moment, that interacts with an e.f.g. to give rise to two sublevels, $\mid \pm 1 / 2>$ and $\mid \pm 3 / 2>$. Therefore, the resonant absorption of $\gamma$-rays by the ${ }^{119} \mathrm{Sn}$ nuclide for each tin site will give either a doublet $(| \pm 1 / 2>\rightarrow| \pm 1 / 2>$ and $| \pm 1 / 2>\rightarrow| \pm 3 / 2>$ transitions), or a singlet $(| \pm 1 / 2>\rightarrow| \pm 1 / 2>$ only), depending on whether there is an e.f.g. acting at the nucleus or not. No hyperfine magnetic field (6 lines) was observed since tin is diamagnetic in all its oxidation states, there was no transferred field in any of the compounds studied since they are diamagnetic and no external magnetic field was applied. The line position is called isomer shift $\delta$, and it is a function of the amount of valence $s$ density acting at the nucleus. This makes it a function of the oxidation state of tin, of the mode of bonding and of the electronegativity of the elements bonded to tin. To a lesser extent, it is also a function of temperature (second order Doppler shift). In Fig. 1A, the $\mathrm{Sn}^{2+}$ stannous ion gives a single peak at high isomer shift (ca. $4 \mathrm{~mm} / \mathrm{s})$. The line is a singlet because the lone pair is located on the native $5 s$ orbital that is are spherical and therefore it generate no e.f.g. The fact that the lone pair is purely $5 s$ makes it that its electron density is unshared and therefore 

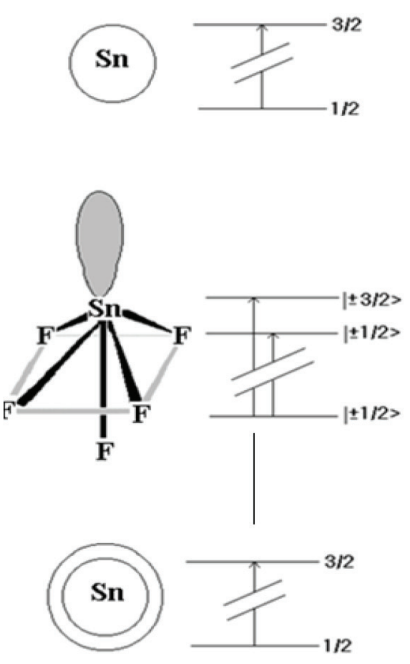
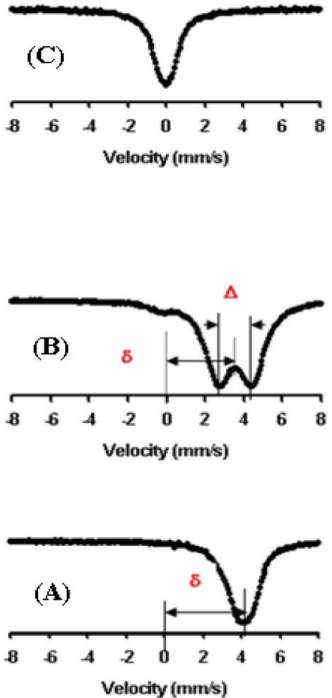

Figure 1: Mössbauer spectra for, (A) Ionic $\mathrm{Sn}^{2+}$, (B) Covalently bonded $\mathrm{Sn}$ (II) in $\mathrm{BaSnF}_{4}$, and (C) $\mathrm{CaSnO}_{3}$.

there is a non-negligible amount of $5 s$ electron density acting at the nucleus, resulting in a high isomer shift. An e.f.g. due to lattice distortion is possible; however, its effect on the spectrum is much weaker. Figure 1B shows the case of tin(II) covalently bonded to fluorine. The stereoactive lone pair at tin generates a very large e.f.g.; hence, a large doublet is observed. Since the $5 s$ electron density is shared between the lone pair and the bonds, it is further away from the nucleus than in the case of ionic bonding, and this generates a smaller isomer shift. Figure $1 \mathrm{C}$ is the spectrum of $\mathrm{CaSnO}_{3}$. It contains $\mathrm{Sn}^{4+}$ ions that have completely lost their valence shell, therefore there is no more $5 s$ electron density acting at the nucleus. It results in a much smaller isomer shift, that is taken as reference of isomer shifts, hence $0 \mathrm{~mm} / \mathrm{s}$, since all isomer shifts are referenced to $\mathrm{CaSnO}_{3}$ at ambient temperature. It gives a single line since $\mathrm{CaSnO}_{3}$ has the perovskite structure where the $\mathrm{Sn}^{4+}$ ions are in an octahedral site. It results from the above that the information obtained for each tin site are (1) its oxidation number, and in this study, for tin(II), (2) the identification of the non-metal bonded to tin, (3) the tin site distortion and (4) the tin type of bonding (ionic or covalent). Figure 1 shows the influence of oxidation number and type of bonding on the Mössbauer spectrum. In addition, the lattice strength can also be estimated. Resonant absorption of $\gamma$-photons is necessary in order to produce a Mössbauer spectrum, and less and less of this occurs when temperature increases and when the lattice is weak, due to phonons. Therefore, a weak lattice will result in a weaker spectrum.

\section{MATERIAL PREPARATION AND CHARACTERIZATION}

The following starting materials were used: $\mathrm{SnF}_{2} 99 \%$ from Ozark Mahoning, $\mathrm{BaCl}_{2} \cdot 2 \mathrm{H}_{2} \mathrm{O}$ analytical grade from American Chemicals, $\mathrm{BaF}_{2} 99 \%$ from Allied Chemicals and Dye Corporations, $\mathrm{HF} 40 \%$ aqueous solution from Mallinckrodt, and doubly distilled or deionized water. All crystalline reactants were checked by X-ray powder diffraction and were found to have only the expected peaks. In addition, $\mathrm{SnF}_{2}$ was checked by DTA and identified by the $\alpha \rightarrow \gamma$ 
transition at $150^{\circ} \mathrm{C}-160^{\circ} \mathrm{C}$ and melting point at $215^{\circ} \mathrm{C}$ [3]. The degree of hydration of $\mathrm{BaCl}_{2} \cdot 2 \mathrm{H}_{2} \mathrm{O}$ was checked by TGA and found to be 2.04 . The production of anhydrous $\mathrm{BaCl}_{2}$ was verified by dehydrating the dihydrate at $140^{\circ} \mathrm{C}$, significantly above the reported dehydration temperature of $113^{\circ} \mathrm{C}$ to ensure complete dehydration [4]. Total loss of water was confirmed by the mass loss of $14.71 \%$ (theoretical for $2 \mathrm{H}_{2} \mathrm{O}=14.75 \%$ ). To ensure that dry anhydrous $\mathrm{BaCl}_{2}$ was obtained for use in the syntheses, $\mathrm{BaCl}_{2} \cdot 2 \mathrm{H}_{2} \mathrm{O}$ was heated at $200^{\circ} \mathrm{C}$ for two hours in air, and then placed under vacuum in the port of a nitrogen glove box while still hot to prevent rehydration. Further handling was carried out under dry nitrogen.

All the materials investigated in this study were prepared either by precipitation or by solid state reactions in dry conditions. Solid state reactions were carried out by heating intimately mixed powders of the reactants in a sealed copper tube under dry nitrogen, according to the method developed by one of us (GD) [5]. One of the methods of preparing $\mathrm{BaClF}$ was to add a limited amount of $40 \% \mathrm{HF}$ to an aqueous solution of $\mathrm{BaCl}_{2} \cdot 2 \mathrm{H}_{2} \mathrm{O}$. The other was to heat a stoichiometric mixture of $\mathrm{BaF}_{2}$ and anhydrous $\mathrm{BaCl}_{2}$ at $400^{\circ} \mathrm{C}$. The $\mathrm{MSnF}_{4}$ compounds were prepared by heating stoichiometric amounts of $\mathrm{SnF}_{2}$ and of $\mathrm{MF}_{2}$ at $250^{\circ} \mathrm{C}$ for $\alpha-\mathrm{PbSnF}_{4}$ and at $500^{\circ} \mathrm{C}$ for $\mathrm{BaSnF}_{4}$ according to the conditions determined earlier by one of us (GD) [6]. The $\alpha$-phase of $\mathrm{PbSnF}_{4}$ was also prepared by precipitation upon adding a solution of $\mathrm{Pb}\left(\mathrm{NO}_{3}\right)_{2}$ to a solution of $\mathrm{SnF}_{2}$ upon stirring, for a molar ratio very rich in $\mathrm{SnF}_{2}\left(\mathrm{SnF}_{2} /\right.$ $\left.\mathrm{Pb}\left(\mathrm{NO}_{3}\right)_{2}=4: 1\right)$ [6]. $\mathrm{K}_{3} \mathrm{Sn}_{5} \mathrm{Cl}_{3} \mathrm{~F}_{10}$ crystals were obtained, mixed with crystals of other compounds, upon slow evaporation of an $\mathrm{H}_{2} \mathrm{O} / \mathrm{HF}$ solution of $\mathrm{KCl}$ and $\mathrm{SnF}_{2}$ in the ratio $\mathrm{KCl}: \mathrm{SnF}_{2}$ equal to 2:1, after gentle warming to make it supersaturated [7].

X-ray powder diffraction was carried out by use of a Philips PW1050 diffractometer that had been automated with the Sie112 Sietronics ${ }^{\circledR}$ system from Difftech. This allowed a phase identification of phases already known, by comparison with the diffraction patterns of starting materials and other possible side products already collected in our laboratory and by use of the $\mu$ PDSM Micro Powder Diffraction Search Match ${ }^{\circledR}$ from Fein-Marquat. Only the phases of interest in this study were subjected to further analysis.

The Mössbauer spectra were recorded using the following setup. The source was a nominally $25 \mathrm{mCi} \mathrm{Ca}{ }^{119 m} \mathrm{SnO}_{3} \gamma$-ray source from Ritverc $\mathrm{GmbH}$. Isomer shits were referenced relative to a standard $\mathrm{CaSnO}_{3}$ absorber at ambient temperature. The counting system was a scintillation counter from Harshaw, equipped with a $1 \mathrm{~mm}$ thick (Tl)NaI crystal. A palladium foil was used to absorb the $25.04 \mathrm{keV}$ and the $25.72 \mathrm{keV}$ X-ray lines generated by the source decay from the $11 / 2$ spin level of the ${ }^{119 m} \mathrm{Sn}$ precursor to the $3 / 2$ spin of the first excited state. The Doppler velocity $( \pm 10 \mathrm{~mm} / \mathrm{s})$ was generated by use of an Elscint driving system, including a Mössbauer MVT-4 velocity transducer, a Mössbauer MDF-N-5 waveform generator and a MFG-N-5 driver. The amplifier, the single channel analyzer and the multichannel analyzer are combined in the Tracor Northern TN7200 system. After, the data were transferred to a computer for storage and processing. Low temperature spectra were recorded using an ADP Cryogenics helium closed-cycle refrigerator equipped with a two-stage Displex ${ }^{\circledR}$. Computer processing of the data was performed using the MOSGRAF-2009 suite [8].

\section{RESULTS AND DISCUSSION}

\subsection{From randomly oriented $\mathrm{BaF}_{2}$ to preferred orientation in $\mathrm{BaClF}$}

$\mathrm{BaF}_{2}$ has the well-known fluorite type structure $\left(\mathrm{CaF}_{2}\right.$ type). It has a cubic unit-cell (Fm3m space group), and a cubic coordination of the cation (Fig. 2B) [9]. This makes the structure 


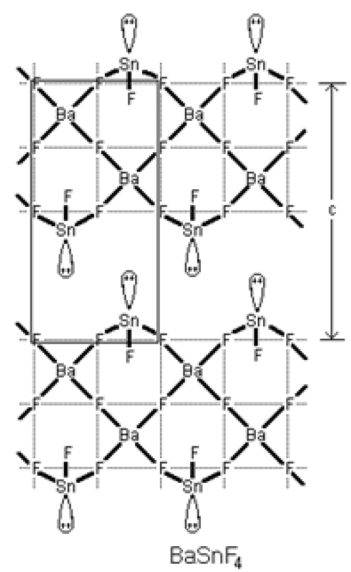

(A)

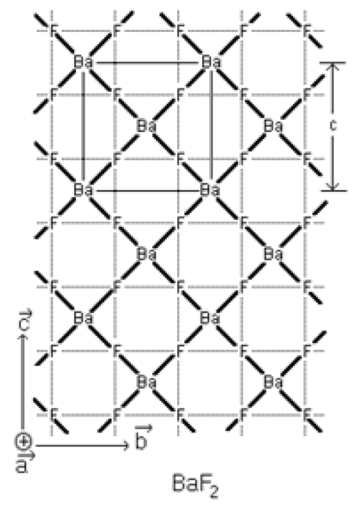

(B)

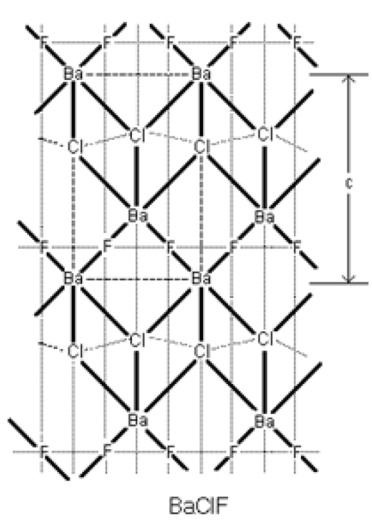

(C)

Figure 2: Projection of the structures of (A) extreme case of anisotropy in $\mathrm{BaSnF}_{4}$, (B) fully isotropic $\mathrm{BaF}_{2}$ and $(\mathrm{C})$ mildly anisotropic $\mathrm{BaClF}$.

fully isotropic, and therefore totally three-dimensional. When every second layer of fluoride ions are replaced by chloride ions to give the alternating sheet sequence ... $\mathrm{F} \mathrm{Cl} \mathrm{F} \mathrm{Cl...,} \mathrm{the}$ tetragonal $\mathrm{BaClF}$ structure (space group $\mathrm{P} 4 / \mathrm{nmm}$ ) is obtained (PbClF type) (Fig. 2). Since the size of the chloride ions is substantially larger than that of the fluoride ions (radii $\mathrm{F}^{-}=1.17$ $\AA, \mathrm{Cl}^{-}=1.67 \AA$ ) [10], and the size of the $\mathrm{BaClF}$ structure in the $(a, b)$ plane of the tetragonal unit-cell is determined by the size of the $\mathrm{Ba}^{2+}$ and the $\mathrm{F}^{-}$ions, the bulkier $\mathrm{Cl}^{-}$ions cannot fit in planes parallel to the $\mathrm{F}^{-}$plane. To overcome this lack of sufficient space, the $\mathrm{Cl}^{-}$ions shift alternatively up and down parallel to the $c$ axis of the unit-cell (Fig. 2C). It results a very substantial elongation of the $c$ unit-cell parameter: for $\mathrm{BaF}_{2} a=b=c=6.2001 \AA$, for $\mathrm{BaClF}$ $a \sqrt{ } 2=b \sqrt{ } 2=6.152 \AA$ and $c=7.214 \AA$ ( $\sqrt{2}$ in order to compare at the same orientation).

$\mathrm{X}$-ray powder diffraction is an excellent method for detecting the presence of bonding anisotropy in crystal structures since weak bonding or the absence of chemical bonding in some directions will create cleavage planes that will result in preferential orientation in the stacking directions of the crystallites favored by the bonding anisotropy. Each Bragg peak is the result of diffraction by a family of parallel planes. The intensity of each peak is a function of the position of each atom/ion in the unit-cell and the diffracting power of each (proportional to the square of the number of electrons on each atom/ion). In addition, the intensity of each peak is also proportional to the number of diffracting planes in the right orientation. Preferred orientation favors some directions the same way as sheets of papers will naturally stack parallel to one another. Therefore, the relative intensity of the peaks shows whether there is preferred orientation, and if there is, the peak Miller indices will show what is the preferred direction. Figure 3 shows the effect of running several times the X-ray diffraction pattern of the same sample of $\mathrm{BaClF}$, with mild hand grinding in a mortar with a pestle in between each run. It can be seen that the relative intensity of the (002) peak and of the (110) peak changes from one run to the text (Fig. 3a-e). When reduced crystal dimensionality is present, it is about impossible to get the same sample twice with the same degree of preferred orientation. The variations of relative peak intensities from run to run are very much characteristic of preferred orientation. In addition, it can be seen from the first run (Fig. 2a) to the 

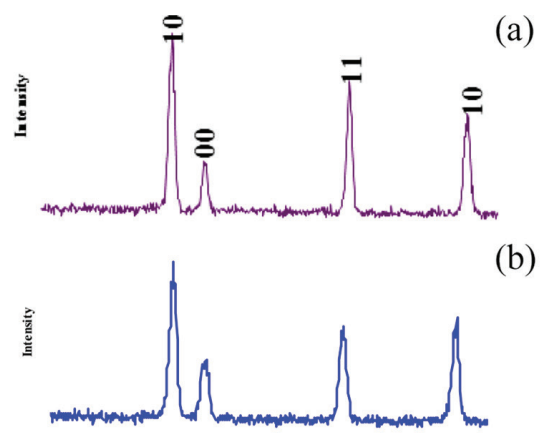

(b)

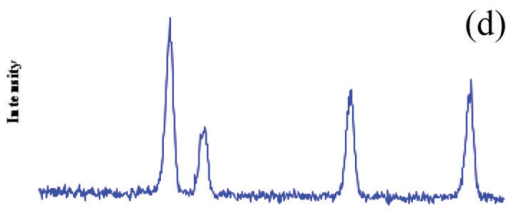

(c)

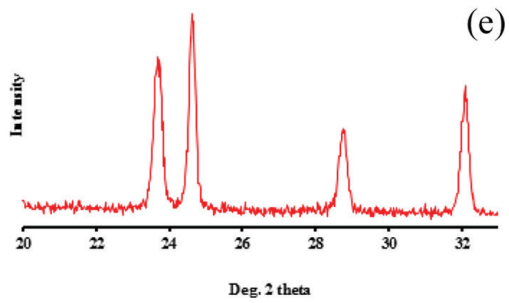

Figure 3: Effect of mixing the specimen between each runs on the relative intensity of (001) and $(\mathrm{hk} 0)$, of pure $\mathrm{BaClF}(\mathrm{x}=0$ and $\mathrm{y}=0)$ prepared by direct reaction at $350^{\circ} \mathrm{C} / 43$ hours, (a) first run, (b) second run, (c) third run, (d) fourth run and (e) fifth run.

next, all the way to the last (Fig. 2e), that the intensity of the (002) peak keeps increasing, while that of the (110) keeps decreasing. This is not surprising that all (001) peaks are due to diffraction by planes perpendicular to the $c$ axis, while all (hk0) peaks, including (110), are due to planes that are parallel to the $c$ axis, therefore the more crystallites are stacked to favor (001), the less of (110) are in position to diffract. Just a slight pressure from the pestle on the powder in the mortar is sufficient to favor parallel alignment of the (001) planes, i.e. the planes parallel to the $(a, b)$ face of the unit-cell, hence a reinforcement of the (002) peak and a weakening of the (110) peak. Examination of the bonding should explain why this preferred orientation. Figure 2 shows that each layer of barium ions is located between a flat layer of fluoride ions and a corrugated sheet of chloride ions. Each layer of fluoride ion is in-between two layers of barium ions, and so is each corrugated sheet of chlorides ions. It results that the layer stacking along the $c$ axis is the following: ... F Ba $\mathrm{Cl} \mathrm{Ba} \mathrm{F} \mathrm{Ba} \mathrm{Cl} \mathrm{Ba} \mathrm{F}$... The weakest points of the structure are the $\mathrm{Ba}-\mathrm{Cl}$ bonds. For an ionic structure, the attraction between $\mathrm{Ba}^{2+}$ cations and $\mathrm{F}^{-}$or $\mathrm{Cl}^{-}$anions is determined Coulomb's law: the attraction is proportional to the product of the charges $Q^{+}$and $Q^{-}$of the ions and inversely proportional to the distance $d$ between them (distance between their nuclei by definition). Since the charge of the two anions is the same, the only difference is their size (radii $\mathrm{F}^{-}=1.17 \AA, \mathrm{Cl}^{-}=1.67 \AA$ ) [10]. It results that the $\mathrm{Ba}^{2+}-\mathrm{Cl}^{-}$ionic bond is significantly weaker than the $\mathrm{Ba}^{2+}-\mathrm{F}^{-}$bond. Therefore, the $\mathrm{BaClF}$ structure is made of the following layers, perpendicularly to the $c$ axis: strongly bonded $\left[\mathrm{Ba}-\mathrm{F}_{2}-\mathrm{Ba}\right]^{2+}$ layers normal to the $c$ axis, interspaced with $\mathrm{Cl}^{-}$corrugated sheets (Fig. $2 \mathrm{C}$ ), that are more weakly bonded to the cationic $\left[\mathrm{Ba}-\mathrm{F}_{2}-\mathrm{Ba}\right]^{2+}$ sheets, and the chloride sheets make the weak part of the structure, providing some amount of cleavage parallel to $(a, c)$, hence some amount of two-dimensionality that will result in the preferred orientation observed by X-ray diffraction. 
4.2 The most extreme cases of two-dimensionality: $\mathrm{SnO}, \mathrm{PbO}$ and $\mathrm{MSnF}_{4}(\mathrm{M}=\mathrm{Ba}$ and $\mathrm{Pb})$

While in $\mathrm{BaClF}$, the preferred orientation originated in the weaker link provided by the corrugated sheets of chloride ions, a much more efficient way of making a two-dimensional structure is to have no chemical bond at all between sheets that have strong bonds within them. Graphite achieves this by using all its valence electrons to form bonds within the sheets, while in $\mathrm{SnO}$ and in yellow $\mathrm{PbO}$, layers of lone pairs from tin(II) precludes interlayer bonding. The X-ray diffraction pattern of $\mathrm{BaSnF}_{4}$ shows the same kind of variation of the relative intensities of the (110) and of the (001) peaks, as can be seen on Fig. 4. The broadening of the (004) peak in Fig. 4b indicates that the sample is microcrystalline parallel to the $c$ axis, due to more efficient cleavage. It results that in $\mathrm{BaSnF}_{4}$, there is also layering with cleavage planes normal to the $c$ axis of the unit-cell. The unit-cell is also a tetragonal distortion of the fluorite type $\mathrm{BaF}_{2}$; however, unlike in $\mathrm{BaClF}$, there is also a superstructure along the $c$ axis, due the ... Ba Ba Sn Sn ... ordering (Fig. 2). The unit-cell axes of the three structures are related as follows: $a, a, a$ in $\mathrm{BaF}_{2}, a / \sqrt{2}, a / \sqrt{2}, c$ in $\mathrm{BaClF}$, and $a / \sqrt{ } 2, a / \sqrt{2} 2,2 c$, in $\mathrm{BaSnF}_{4}$. The layer ordering parallel to the $c$ axis in $\mathrm{BaSnF}_{4}$ is the following, whereby $\mathrm{LP}$ are the sheets of lone pairs:

\section{... LP Sn F Ba F Ba F Sn LP Sn F Ba F Ba F Sn LP ...}

The layers of lone pairs create very efficient cleavage planes. A short time ball-milling (2 minutes) results in a large enhancement of the (004) peak, at the expenses of the (110) peak, similar to the effect of manual grinding of $\mathrm{BaClF}$ (Fig. 5). It can be seen that the (001) and (002) peaks are also stronger after milling, since all (001) peaks are due to parallel planes, parallel to the cleavage planes (Fig. 2A). The X-ray diffraction pattern of $\alpha-\mathrm{PbSnF}_{4}$ shows a much more extreme case of preferred orientation (Fig. 6). The (001), (002) and (004) peaks

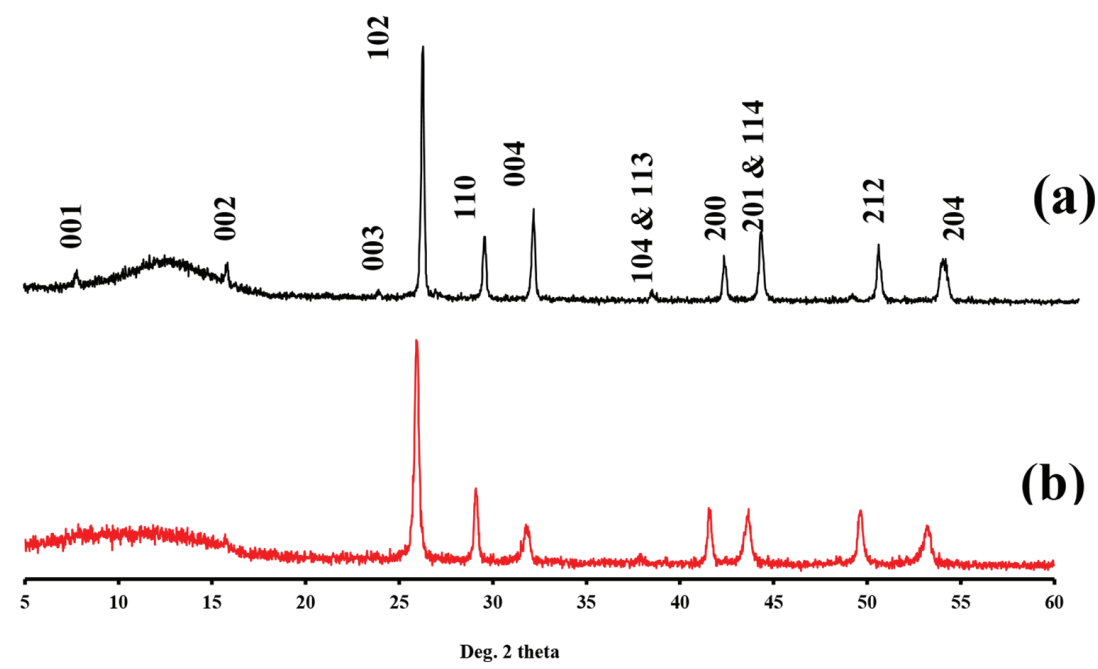

Figure 4: X-ray powder diffraction patterns of two samples of $\mathrm{BaSnF}_{4}$ : (a) prepared in dry conditions at $400^{\circ} \mathrm{C}$, (b) obtained by leaching $\mathrm{BaSnCl}_{3} \cdot 0.8 \mathrm{H}_{2} \mathrm{O}$ in water. Sample (b) shows less preferred orientation and some amount of microcrystallinity in the direction of the $c$ axis of the tetragonal unit-cell (line broadening). 

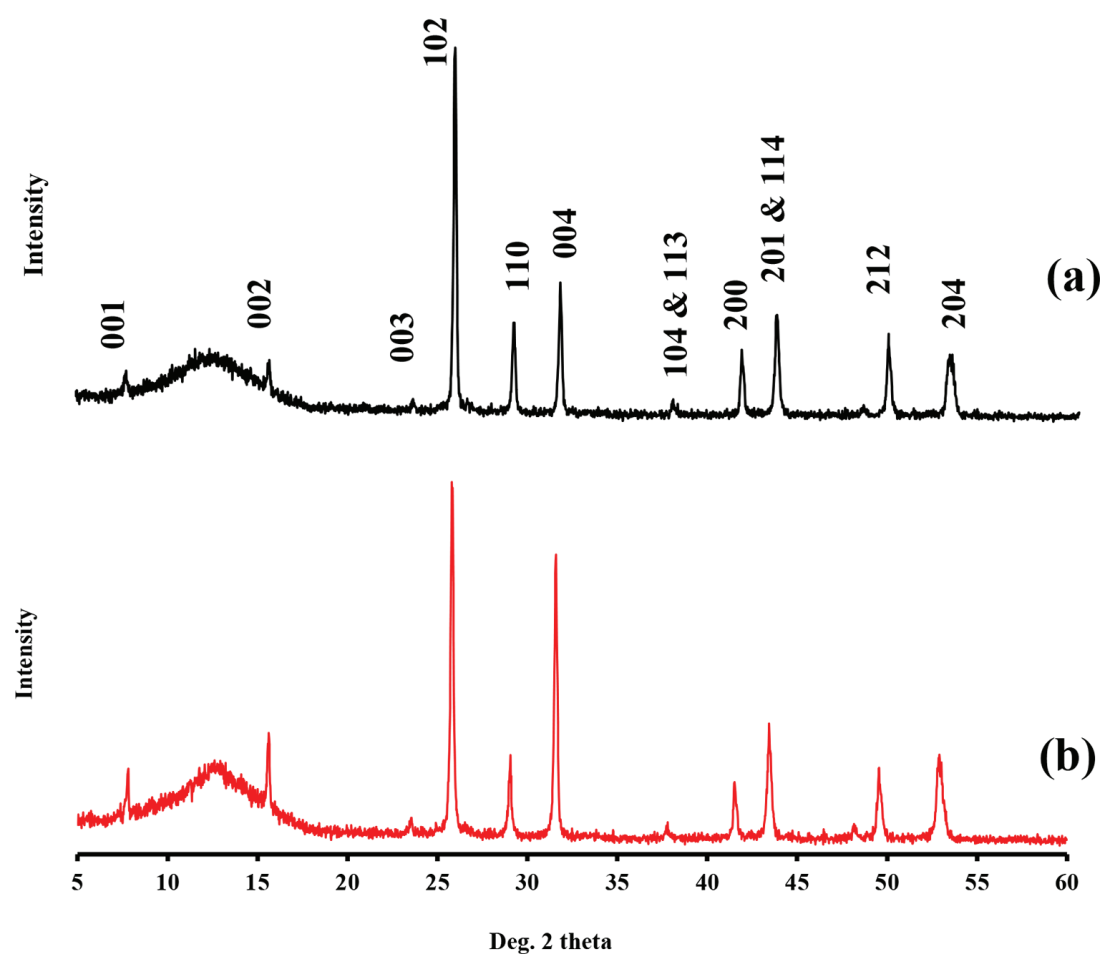

Figure 5: Effect of mild ball-milling on layered $\mathrm{BaSnF}_{4}$ : (a) before milling, (b) after milling for 2 minutes. The strong enhancement of the (001) peaks after 2 minutes of milling shows a strong enhancement of the preferred orientation.

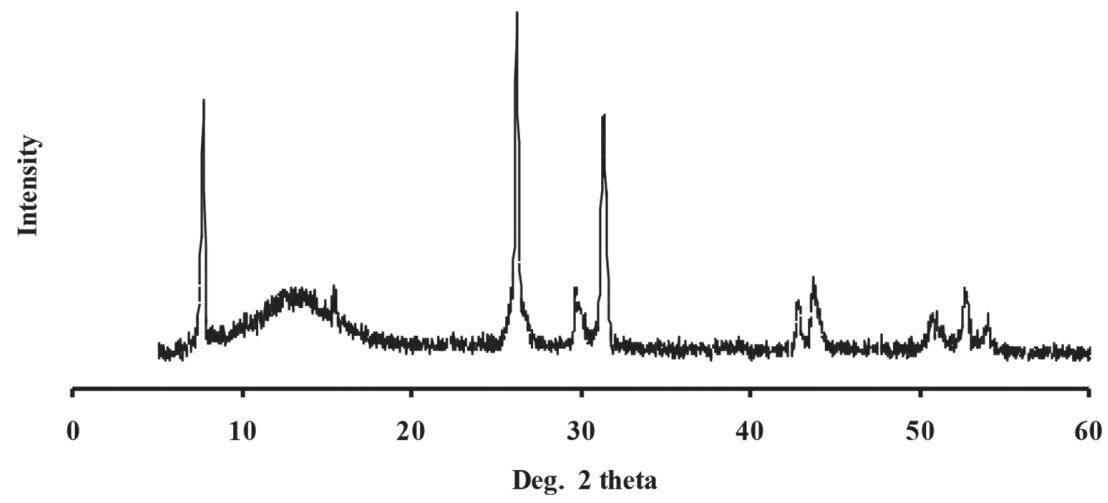

Figure 6: X-ray powder diffraction of $\alpha-\mathrm{PbSnF}_{4}$ : an extreme case of preferred orientation, as seen by the very high intensity of $(001)$ at $2 \theta \approx 8^{\circ}$ and $(004)$ at $2 \theta \approx 32^{\circ}$, compared to the weak (110) peak at $2 \theta \approx 30^{\circ}$.

are very strong, while (110), representative of the perpendicular direction, is weak. This is not surprising, taking into account that the crystals of precipitated samples are large very thin sheets, than can be of over $1 \mathrm{~cm}^{2}$ surface area, while being too thin to be collected in the form of separate single crystals. They just break apart. However, filtering such sample on a Büchner 
funnel with the aspiration of a water pump, promotes the parallel stacking of the large sheet shaped crystallites, the same way as pieces of sheets of paper will also stack parallel to one another. When a sample collected this way is allowed to dry on the filter paper without disturbance, it peels off the filter paper and then it was glued to an X-ray powder diffraction sample holder. The resulting X-ray diffraction pattern showed only very strong (001) peaks, while the only other peak detected was a very weak (102) at ca. $25.5^{\circ} 2 \theta$, showing that nearly perfect parallel stacking was achieved, the same way as the pages of a book are parallel to one another when the book is closed. However, this alignment applies only parallel to the $c$ axis. No assumption is made about the direction of the $a$ and $b$ axes, other than they lie in the plane of the sheets, however, for each crystal. they can be in any direction within the plane of the sheets. The large two-dimensionality of the $\mathrm{MSnF}_{4}$ samples is due to the sheets of lone pairs from tin being cleavage planes. This requires that the tin lone pair must be stereoactive, and using highly oriented samples, the orientation of the lone pairs relative to the unit-cell axes can be determined. Figure 7 shows the ${ }^{119} \mathrm{Sn}$ Mössbauer spectrum of a very nearly perfectly oriented sheet sample of $\alpha-\mathrm{PbSnF}_{4}$ the X-ray diffraction pattern of which gives only the (001) peaks, showing that the $c$ axis of the unit-cell of all the crystals contained in the sheet is perpendicular to the sheet. The spectrum was recorded versus the orientation of the sheet in the $\gamma$-ray beam. The spectrum is a large quadrupole doublet with an isomer shift $\delta=3.24(1) \mathrm{mm} / \mathrm{s}$ and a quadrupole splitting $\Delta=1.57(2) \mathrm{mm} / \mathrm{s}$. These spectra are very much like that of Fig. 1B and confirm that the tin lone pair is stereoactive and that bonding is covalent with the lone pair being located on a hybrid orbital. It can be seen that when the $\gamma$-ray beam is perpendicular to the sheet, the Mössbauer doublet is highly asymmetric (Fig. 7a); however, when the sample is rotated at $45^{\circ}$ from the $\gamma$-ray beam, the asymmetry is reduced dramatically. Such a behavior
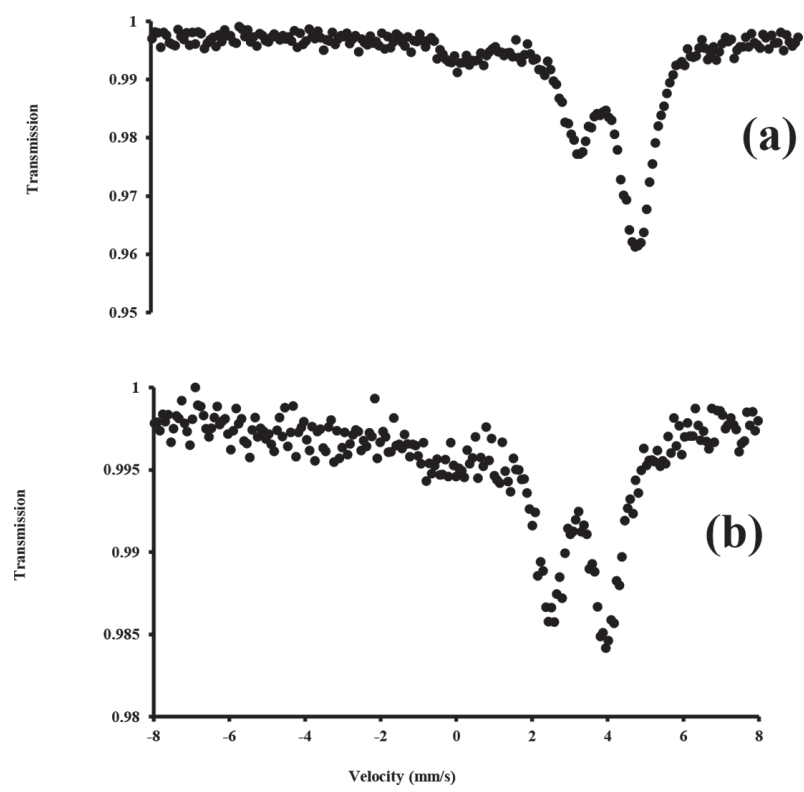

Figure 7. Ambient temperature Mössbauer spectra of highly oriented $\alpha-\mathrm{PbSnF}_{4}$ : change of the asymmetry of the quadrupole doublet with the orientation of the sample relative to the $\gamma$-ray beam direction: (a) $\theta=0^{\circ}$, (b) $\theta=45^{\circ}$. $\theta$ is the angle between the $\gamma$-ray beam and the normal to the plane of the sample. 
is observed in single crystals and in highly oriented polycrystalline samples [11]. The ratio of the intensity of the two lines in a single crystal is the following:

$$
\frac{I_{3 / 2}(\theta)}{I_{1 / 2}(\theta)}=\frac{1+\cos ^{2} \theta}{2 / 3+\sin ^{2} \theta} \neq 1
$$

whereas $\theta$ is the angle between the the $\gamma$-ray beam and $\mathrm{V}_{\mathrm{zz}}$, the main axis of the e.f.g. acting at tin. The spectrum will be symmetrical when the following condition is met:

$$
\mathrm{I}_{3 / 2}(\theta)=\mathrm{I}_{1 / 2}(\theta) \rightarrow 1+\cos ^{2} \theta=2 / 3+\sin ^{2} \theta \rightarrow \theta=\operatorname{Arc} \sin (1 / \sqrt{ } 3)=54.74^{\circ}
$$

For $\theta=54.74^{\circ}$, called the magic angle, the two lines will have the same intensity. It was not possible to measure a Mössbauer spectrum at $\theta=54.74^{\circ}$ because most of the $\gamma$-ray beam was absorbed by the sample and the sample holder at such a high grazing angle, however a spectrum was measured at $45^{\circ}$ (Fig. $7 \mathrm{~b}$ ) and it is clearly much more symmetrical. Obviously, at $54.74^{\circ}$, it would be close to symmetrical. This shows that at $\theta=0^{\circ}$, the $\gamma$-ray beam is parallel to $\mathrm{V}_{\mathrm{zz}}$, and since this direction is normal to the sheet, $\mathrm{V}_{\mathrm{zz}}$ is parallel to $c$. The main contributor to the e.f.g. is $\mathrm{V}_{\mathrm{zz}(\mathrm{val})}$, the imbalance in non-spherical valence electrons ( $p$ and $d$ electrons), $d$ due to the contribution of one or two $5 d$ orbitals to hybridization, and the lone pair, on a hybrid orbital, is the main contributor. This proves that the tin-lone pair axis is parallel to $c$, thereby creating the sheets of lone pairs that are at the origin of the extreme case of two-dimensionality (Fig. 2A). $\mathrm{PbSnF}_{4}$ is the highest performance fluoride ion conductor. The electrical conductivity of $\mathrm{PbSnF}_{4}$ and of of $\mathrm{BaSnF}_{4}$ has been measured on polycrystalline samples, that certainly suffered from preferred orientation $[12,13]$. Taking into account the extreme case of bonding anisotropy, the abilty of the fluoride ions to move must also be highly anisotropic. The conductivity has not been measured versus direction in the crystal so far, most likely because of technical difficulties in carrying out measurements in different directions of the crystals, owing to the crystal shape of extremely thin sheets that break apart as soon ones tries to isolate one.

\subsection{A case of one-dimensionality in $\mathrm{M}_{3} \mathrm{Sn}_{5} \mathrm{Cl}_{3} \mathrm{~F}_{10}\left(\mathrm{M}=\mathrm{K}\right.$ and $\left.\mathrm{NH}_{4}\right)$}

The $\mathrm{M}_{3} \mathrm{Sn}_{5} \mathrm{Cl}_{3} \mathrm{~F}_{10}\left(\mathrm{M}=\mathrm{K}\right.$ and $\mathrm{NH}_{4}$ ) compounds have needle-shaped crystals (one-dimensional). The crystal structure of $\mathrm{M}_{3} \mathrm{Sn}_{5} \mathrm{Cl}_{3} \mathrm{~F}_{10}$ shows the type of arrangements shown on

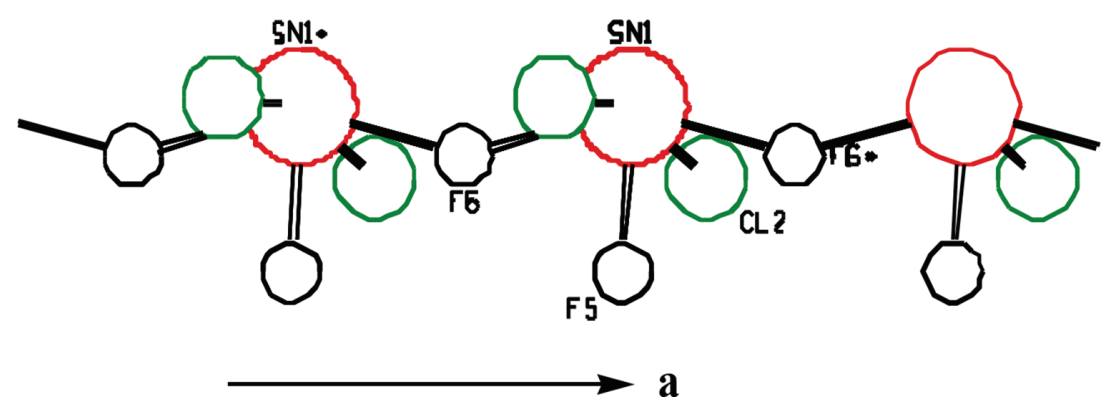

Figure 8: Polymerization of the $\left[\mathrm{SnCl}_{2} \mathrm{~F}_{3} E\right]^{3-}$ units to form $\left[\mathrm{SnCl}_{2} \mathrm{~F}_{2} E\right]_{n}{ }^{2 n-}$ chains $\Rightarrow>$ forces the lone pairs to align in the same direction. The lone pair $\mathrm{E}$ is in trans-position to F5. 


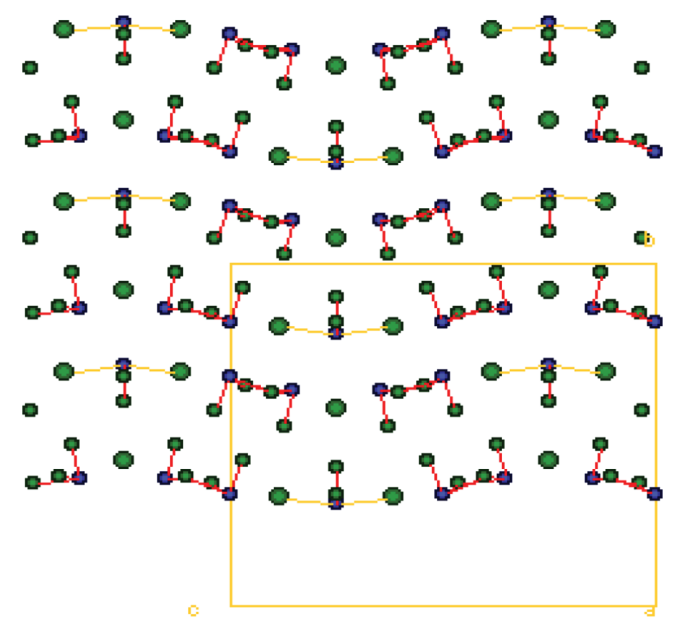

Figure 9: $\mathrm{M}_{3} \mathrm{Sn}_{5} \mathrm{Cl}_{3} \mathrm{~F}_{10}\left(\mathrm{M}=\mathrm{NH}_{4}\right.$ and $\left.\mathrm{K}\right)$ : The lone pairs are clustered in sine wave-shaped sheets, creating a two-dimensional assembly, however sheets of lone pairs in another direction intersect this assembly to give needle-shape crystals (one-dimensional)

Figs. 8 and 9 [7]. Polymerization using bridging fluorine atoms (F6 on Fig. 8) forces the tin lone pairs of a chain to align parallel to one another. Tin has an octahedral electron pair geometry, $\mathrm{sp}^{3} \mathrm{~d}^{2}$ hybridization, i.e. with six effective pairs: 5 bonding pairs ( 1 bond to a terminal F, 2 bonds to bridging $\mathrm{F}$ and 2 bonds to chlorine) and a lone pair, resulting in a distorted square pyramidal molecular geometry, in agreement with the VSPER model [14], with the E shape according to Brown [15] and the $\mathrm{SnF}_{5} \mathrm{E}$ octahedral model of Galy et al. [16].

\section{CONCLUSION}

It was found in this study that, unless the crystal system is cubic, property anisotropy can be present. While it is mild in many cases, it can be extremely strong in others. Anisotropic properties are due to bonding anisotropy. This can be due to weaker bonds in particular directions, like in the case of $\mathrm{BaClF}$. The most extreme cases occur when there is no bonding at all in some directions. This occurs when lone pairs from weak metals in a suboxidation state cluster in sheets. It has been observed to take place in $\mathrm{MO}(\mathrm{M}=\mathrm{Sn}$ and $\mathrm{Pb})$ and in $\mathrm{MSnF}_{4}(\mathrm{M}$ $=\mathrm{Ba}$ and $\mathrm{Pb}$ ). One good way to identify anisotropic structures is to observe preferred orientation by use of X-ray powder diffraction. Changes of relative peak intensity from one run to another on the same sample after mild grinding, or just after putting the sample back on the holder, indicates that preferred orientation occurs, due to some directions in the crystals being favored. The Miller indices of the peaks of concern gives the orientation of the cleavage planes in the unit-cell. Tin-119 Mössbauer spectroscopy identifies unambiguously the oxidation number and bonding type of tin, and if it is covalent, it confirms the stereoactivity of the lone pair, and when spectra are run on very highly oriented samples versus their orientation in the crystal, it can also give the orientation of the lone pairs and confirm that they are responsible for the cleavage. A case of intersecting cleavage planes due to lone pairs giving needle shaped crystals was also shown to exist in $\mathrm{M}_{3} \mathrm{Sn}_{5} \mathrm{Cl}_{3} \mathrm{~F}_{10}\left(\mathrm{M}=\mathrm{NH}_{4}\right.$ and $\left.\mathrm{K}\right)$. 


\section{ACKNOWLEDGEMENT}

Professor K. Ruebenbauer, Pedagogical University, Krakow, Poland, is gratefully acknowledged for providing us with the Mosgraf-2009 suite used to process Mössbauer data and for very useful discussions.

\section{REFERENCES}

[1] Nye, J.F., Physical properties of crystals, Oxford University Press (Clarendon), 1957.

[2] Pannetier, J. \& Dénès, G., Tin(II) oxide: structure refinement and thermal expansion. Acta Crystallographica, B36, pp. 2763-2765, 1980. https://doi.org/10.1107/s0567740880009934

[3] Dénès, G., About $\mathrm{SnF}_{2}$ stannous fluoride, VI. phase transitions. Materials Research Bulletin, 15(6), pp. 807-819, 1980. https://doi.org/10.1016/0025-5408(80)90015-X

[4] Weast, R.C. \& Astle, M.J., editors, CRC handbook of chemistry and physics, 61st ed., CRC Press, In., Boca Raton, Florida, USA, p. B-80, 1980-1981.

[5] Dénès, G., The bent copper tube: a new inexpensive and convenient reactor for fluorides of metals in suboxidation states. Journal Solid State Chemistry, 77(1), pp. 54-59, 1988. https://doi.org/ 10.1016/0022-4596(88)90089-8

[6] Dénès, G., Pannetier J. \& Lucas J., Les Fluorures $\mathrm{MSnF}_{4}$ à Structure $\mathrm{PbFCl}(\mathrm{M}=\mathrm{Pb}$, Sr, Ba). C. R. Acad. Sc. Paris, 280(12), pp. 831-834, 1975.

[7] Merazig, H., Setifi, F., Setifi, Z., Bird, P.H., Dénès, G. \& Tam, K., $\mathrm{K}_{3} \mathrm{Sn}_{5} \mathrm{Cl}_{3} \mathrm{~F}_{10}$ with a corrugated layered structure. Acta Crystallographica Section E, 61, pp. i120-i122, 2005. https://doi.org/10.1107/S1600536805016351

[8] Ruebenbauer, K. \& Duraj, Ł., available at: www.elektron.up.krakow.pl/mosgraf-2009

[9] West, A.R., Solid state chemistry and its applications. Wiley, New York, pp. 230-242, 1984.

[10] Shannon, R.D. \& Prewitt, C.T., Revised values of effective ionic radii. Acta Crystallographica Section B Structural Crystallography and Crystal Chemistry, 26(7), pp. 1046-1048, 1970. https://doi.org/10.1107/s0567740870003576

[11] Greenwood, N.N. \& Gibb, T.C., Mössbauer spectroscopy, Chapman and Hall, London, pp. 66-72, 1971.

[12] Villeneuve, G., Echegut, P., Lucat, T., Réau, J.M. \& Hagenmuller, P., Mobilité de l'ion fluor dans PbSnF4. Physica Status Solidi (b), 97(1), pp. 295-301, 1980. https://doi.org/10.1002/pssb.2220970134

[13] Dénès, G., Birchall, T., Sayer, M. \& Bell, M.F., BaSnF 4 - A new fluoride ionic conductor with the $\alpha-\mathrm{PbSnF}_{4}$ structure. Solid State Ionics, 13(3), pp. 213-219, 1984. https://doi.org/10.1016/0167-2738(84)90032-8

[14] Gillespie, R.J. \& Nyholm R.S., Inorganic stereochemistry. Quarterly Reviews Chemical Society, 11, pp. 339-380, 1957.

[15] Brown, I.D., Bond valence as an aid to understanding the stereochemistry of $\mathrm{O}$ and $\mathrm{F}$ complexes of $\mathrm{Sn}(\mathrm{II}), \mathrm{Sb}(\mathrm{III}), \mathrm{Te}(\mathrm{IV}), \mathrm{I}(\mathrm{V})$ and $\mathrm{Xe}(\mathrm{VI})$. Journal of Solid State Chemistry, 11, pp. 214-233, 1974. https://doi.org/10.1016/s0022-4596(74)80006-x 
[16] Galy, J., Meunier, G., Andersson, S. \& Aström, A., Stéréochimie des eléments comportant des paires non liées: $\mathrm{Ge}(\mathrm{II}), \mathrm{As}(\mathrm{III}), \mathrm{Se}(\mathrm{IV}), \mathrm{Br}(\mathrm{V}), \mathrm{Sn}(\mathrm{II}), \mathrm{Sb}(\mathrm{III}), \mathrm{Te}(\mathrm{IV}), \mathrm{I}(\mathrm{V})$, $\mathrm{Xe}(\mathrm{VI}), \mathrm{Tl}(\mathrm{I}), \mathrm{Pb}$ (II) et $\mathrm{Bi}(\mathrm{III})$ (oxydes, fluorures et oxyfluorures). Journal of Solid State Chemistry, 13(1-2), pp. 142-159, 1975.

https://doi.org/10.1016/0022-4596(75)90092-4 